\title{
Design and Use of a Mobile Application to Prevent Teachers' Absenteeism in a Higher Education Setting
}

\author{
https://doi.org/10.3991/ijim.v13i08.10270 \\ Suryaman \\ Universitas Islam Raden Rahmat, Jawa Timur, Indonesia \\ Herri Mulyono $\left({ }^{(x)}\right.$ \\ University of Muhammadiyah Prof. DR. Hamka, Jakarta, Indonesia \\ hmulyono@uhamka.ac.id
}

\begin{abstract}
In this paper, we present a digital application developed to prevent teachers' absenteeism in a private university in Indonesia. In particular, we evaluated the development and the application of an Android-based attendance management system (AAMS) to monitor teachers' attendance and their teaching activity at a private university in the capital city of Jakarta, Indonesia. Adopting a design-based research approach, we observed the development procedure and interviewed three end-users of the application, i.e. teachers. The findings of the study revealed the potential use of AAMS as a digital tool to prevent absenteeism among university teachers. The three main challenges were highlighted during the application of AAMS, including the processing time duration and system error, the reporting and analytics issues, and the input manipulation. Furthermore, a recommendation is offered on the basis of the findings.
\end{abstract}

Keywords-Digital application, attendance management system, teachers' absenteeism, mobile application

\section{Introduction}

Teacher absenteeism is generally viewed as a teacher's intentional or episodic absence from schoolwork [1], [2]. Teachers are said to be absent if the school administrators are not able to find them in the schools for any cause at the time of a random unannounced spot check [3]. With respect to the reason for teachers' absence, Sagie classified teacher absenteeism into either voluntary or involuntary on the basis of the reasons for their absence [4]. Voluntary absences are led by the teachers' direct willingness to not attend a teaching session at school [1]. This type of absenteeism may be a result of job dissatisfaction and a lack of commitment to the institution [5]. The latter is often caused by particular circumstances beyond the control of the teacher, such as illness or discretionary or other conditions such as marriage, mourning and administrative responsibilities [6]-[8].

A body of literature has reported the negative consequences of teacher absenteeism at school on the students' achievement, school management and school expenses, as 
well as the school performance. A study conducted by Danteh, Yaboah, Sam and Monkah [9] in Kumasi, Ghana, for example, revealed that teacher absenteeism significantly lowers the students' performance in Basic Education Certificate Examination (BECE). Similarly, Miller, Murnane, and Willett [10] found that a substantial number of the absences are unauthorised, and a larger number of absences lead to significantly lower student achievement in a large urban school district in the northern part of the United States of America. Abayasekara and Arunatilake [11] also reported that student achievement is low in schools when the number of days of leave taken by the teachers is high. This was demonstrated using descriptive statistics which implied that the average number of teacher leave days was $15 \%$ of the total number of working school days.

In the context of developing countries, teacher absenteeism at schools has been a critical concern for the governments, educational bodies and, apparently, school administrators. A number of studies (i.e. Davies, 2018; Sabarwal \& Sawdeh, 2018; Usman \& Suryadarma, 2007) have found a high rate of teacher absences from their school itinerary. Iqbal, Muhammad, and Haider [15] investigated the causes of absenteeism among 100 public and private school teachers in Punjab, Pakistan. The results indicated that the rate of a public teacher's absence in the school was $54 \%$ per month, while that of the private teachers was $34 \%$. Family reasons and sickness were observed to be the reasons for the absence of the public school teachers, while work dissatisfaction, job insecurity, and the work atmosphere were the reasons for the private teachers' absence in school. In addition, Mooij [16] conducted a longitudinal study in Pradesh, India, on the voluntary teacher absenteeism level. The findings revealed a high teacher absenteeism level because of poor infrastructural facilities, overcrowded classrooms, lack of motivation and inadequate training to deal with multi-lingual classes. The other reasons were related to the school context, such as the absence of rewards or incentives for the teachers to perform well.

More specifically in Indonesian school settings, McKenzie, Nugroho, Ozolins, McMillan, and Sumarto [17] carried out a large-scale study on the teacher absenteeism in Indonesian schools. The study was considered 880 primary and junior secondary schools across six regions-Java, Sulawesi, Sumatra, Kalimantan, Papua and Maluku, and Bali and Nusa Tenggara - including 8,300 teachers and 8,200 students. The researchers observed the classes and conducted interviews with the principals, teachers and district-level officials. They examined not only the teachers' chronic absence from school but also the teachers who, although present in school, did not attend a class or teach as scheduled. Unfortunately, the findings revealed that the teachers' truancy was generally higher in rural schools than in urban schools because the teachers worked at more than one institution and because of poor physical facilities. The truancy occurred over a loss of control from the district education office, school principals, as well as the students' parents or guardians. Moreover, the principal's contribution to the truancy was critical as they did not attend school themselves nor provided a positive role model to the teachers.

Many researchers have identified several factors contributing to teacher absenteeism, one of which concerns a teacher's low effort to attend class. In a recent study, Sabarwal and Jawdeh [12] explored the issue of teachers' low effort to maintain good 
class attendance, particularly the concept of 'mental models' that lead to a teacher's absence in school. Examining the data of 16,000 teachers across developing countries such as Afghanistan, Argentina, Indonesia, Myanmar, Pakistan, Senegal, Tajikistan, and Tanzania (Zanzibar), these researchers found that teacher absenteeism was tolerable under certain conditions. The findings also suggested that many teachers considered the following types of absenteeism to be acceptable at school:

- When the prescribed curriculum had been completed

- When the students were left with assignments to complete

- When the teacher was doing something useful for the society.

The study also showed that teachers in these countries believed that being assessed on the basis of the students' learning was sufficient to determine their performance. Sabarwal and Jawdeh [12] argue that teachers might not seem to increase this effort as they might not think they could or should do so. If teachers are enabled to identify their present levels of work as well as efforts to be "socially optimal and contextually justified, then they are less likely to increase effort in response to a change in the accountability and incentive structures" [12, p. 11].

The recent developments in the field of information and communication technology have offered alternative solutions for monitoring employees' attendance in particular organisations, particularly the teachers' attendance in schools (e.g. Duflo, Esther, Dupas, \& Kremer, 2011; Ujan \& Ismaili, 2011). Many researchers have suggested the use of an attendance management system (AMS), an alternative technology application developed to help an organisation manage manpower notes and analysis, day-today monitoring of attendance, maintenance of statutory registers, monitoring of leave records, calculation of overtime and transfer of the relevant information to the payroll system [20], [21]. AMSs can be generally categorised into four application types, namely manual systems, biometric systems, card-based systems, and e-commerce systems [22].

Baffoe [23] investigated a biometric AMS application called Rapid Application Development (RAD) in the rural educational institutions of Ghana. The findings showed that RAD provided the schools with an efficient way of generating reports and retrieving the attendance information of teachers in the rural districts. However, the application of a biometric system to manage the teachers' attendance can unfortunately raise a number of concerns. For example, for user enrolment, the users' fingerprints should meet the requirements of cleanliness, dryness, and a lack of scratches and/or swelling [24].

In addition to the AMS application, an Android-based e-commerce system has been considered an alternative that enables organisation managers to monitor not only the employees' attendance but also their efficiency [22]. Joshi, Shete, and Somani [25] evaluated an Android-based application for AMS for the advancement of institutional and educational systems in India. The proposed project was implemented in applications such as online study material, announcements of events and examinations, academic calendar, online attendance record, performance record, and even parent intimation system using Android applications. The findings of the study showed that the system helped the teachers to maintain their own attendance through a 
smartphone and to monitor their students with respect to the students' assessments and attendance.

Bhattacharjee, Kundu, Raychaudhuri, and Chakraborty [26] introduced an AMS application compatible with all Android versions starting from 4.2 Jelly Bean. They connected the application to the college server so as to access and update the attendance over the college LAN. The application involved various items such as registration, courses and attendance for various purposes which shall be discussed later. The application allowed the addition of courses by the teacher and the addition of students to the respective courses. When a course was ready, it was visible in the selection area for marking attendance, checking the attendance percentage and even checking the date-wise attendance. After the app integration, the researchers found that the Android-based attendance application operated at a high level of efficiency. It appeared to be safe, easy and less time consuming. The app was user friendly and did not require the user to be close to the main system. Finally, the findings suggested that the storage, retrieval and evaluation of the users' data were performed with minimal errors and within the smallest-possible amount of time.

Investing in a system that keeps teachers present in the classroom should be considered as a priority for school managements, administrators and policymakers. A key part of this effort is to develop an appropriate school system which captures the daily attendance of the faculty members, generates faculty attendance reports and analytics, provides an absence notification system for the faculty members, chairperson and the dean, and includes an immediate communication system concerning the absences incurred [27]. The current study aimed at evaluating the development and application of an Android-based AMS (AAMS) to monitor teachers' attendance and their teaching activity at a private university in the capital city of Jakarta, Indonesia. To this end, the study documented the structure and the development process of AAMS and explored the perceptions of teachers towards the use of such an application to monitor their attendance and teaching activities.

\section{$2 \quad$ Method}

The current study was a part of a bigger project evaluating the role of technology to prevent teachers' absenteeism in higher education settings. In the study, we evaluated the development and application of AAMS to monitor teachers' attendance and their teaching activity at a private university in the capital city of Jakarta, Indonesia. To this end, the study documented the structure and the development process of AAMS and explored the perceptions of three teachers about the use of such an application to monitor their attendance and teaching activities in the classroom.

The study adopted a design-based research (DBR) approach to address the research objective. In educational research, Fishman, Penuel, Allen, Cheng, and Sabelli [28] argued that DBR allowed the researcher to design and test a particular innovation within real-world educational settings. The main objective of this research approach is to enable 'the impact of educational research and generate generalisable design principles' $[29$, p. 16]. To this end, in the current study, we worked closely with IT devel- 
opers to gain the insights from the AAMS development procedure and observed the application of AAMS at a private university. We also explored the perception of three teachers as the end-users.

\section{$3 \quad$ Narrative Development and Findings}

The AAMS considered in the current study was an Android-based application developed to provide a system interface that monitors teacher attendance in classrooms. The interface system, later called U-Mobile, uses a client-server based model to allow engagement between clients and servers [30]-[33]. The system was developed using several tools, including MySQL server database, Apache, Android Apps Native and Application Programming Interface (API). U-Mobile was connected to a phone's GPS which limited the access of the application only to a particular position. This restricted the potential attempts by teachers to manipulate the data input.

To use U-Mobile, teachers were asked to download the application from Google Play Store and install it on their mobile phones. After the installation, the teachers were asked to $\log$ in to the application by using the usernames and passwords already given to them by the faculty administration. Figure 1 shows the login page and the welcome screen.
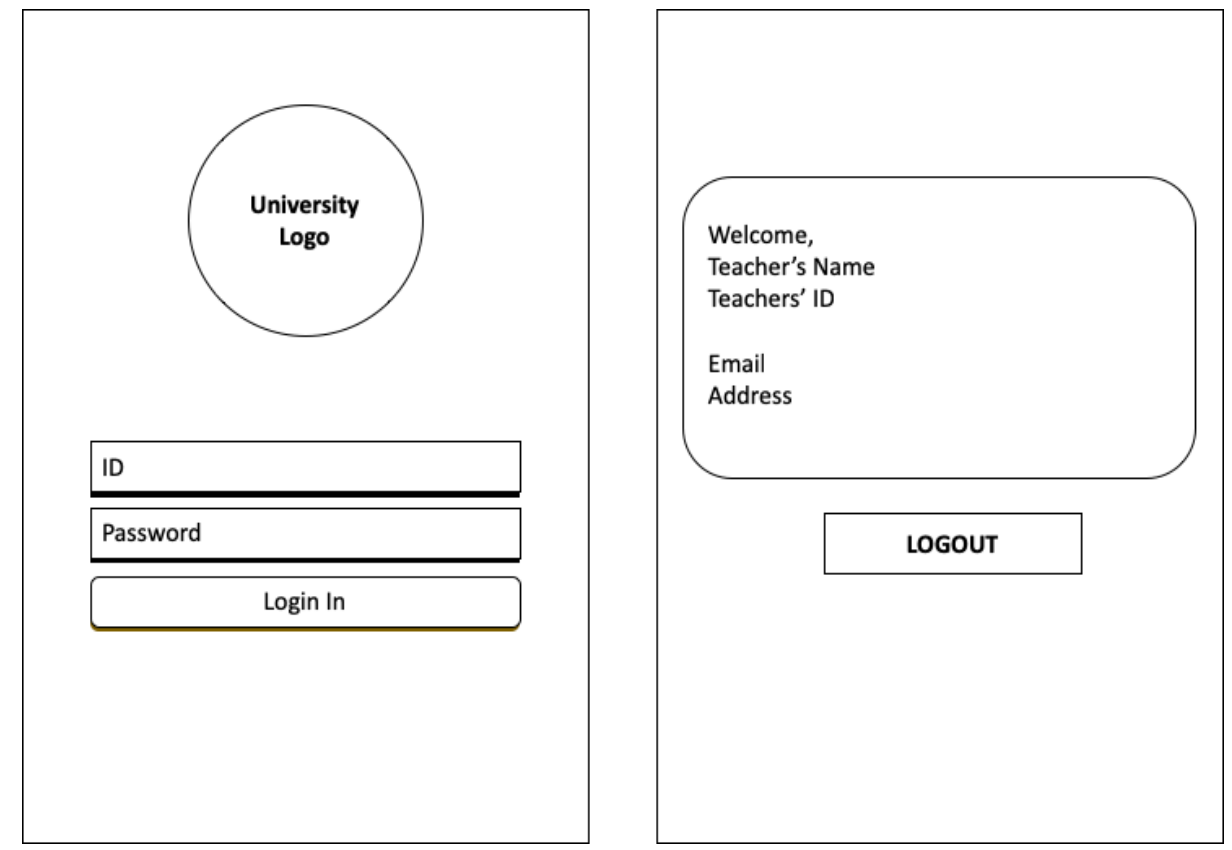

Fig. 1. Login page (left) and welcome screen (right)

U-Mobile features 12 menus, including attendance, teaching schedule, students under supervision (PA), examination schedule (exam), essay, supervisory schedule, 
information, room, two next menus, chat and help desk (see Figure 2). Unfortunately, six of these twelve menus did not function well or did not work at all (e.g. users were unable to click on information, two next menus, chat and help desk).
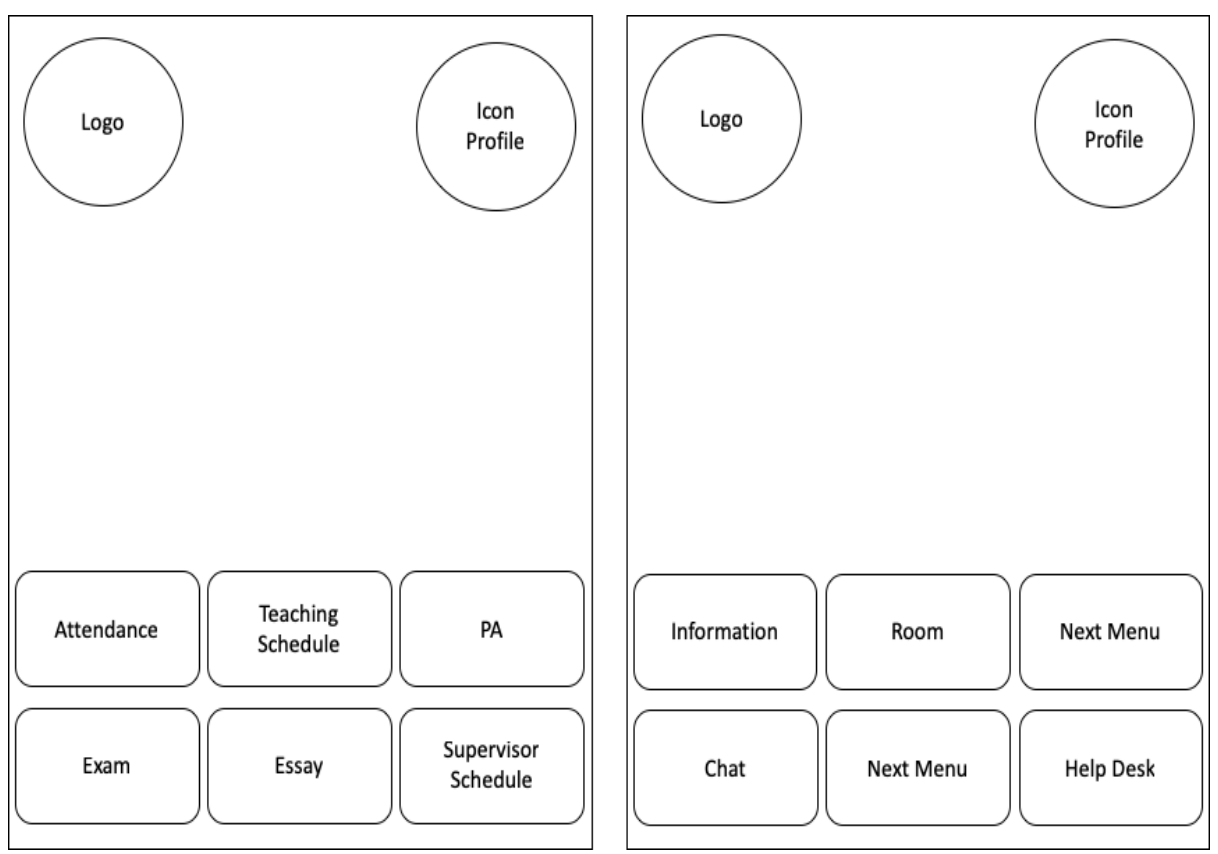

Fig. 2. Screen menu page 1 (left) and screen menu page 2 (right)

Of these 12 menus, the attendance feature was used by the faculty administration to monitor both teachers and students. The feature required the teachers to complete three tasks: check students' attendance in the classroom, describe the topic being taught and save the data to the system (see Figure 3). In each teaching session, first, the teachers had to monitor their students' entry into the classroom and check their name in the application to mark their attendance. Teachers were also required to record the topics that they were teaching at the time and save them to the system. Teachers were counted as present in the class only if they completed these tasks and the save operation was successful. 


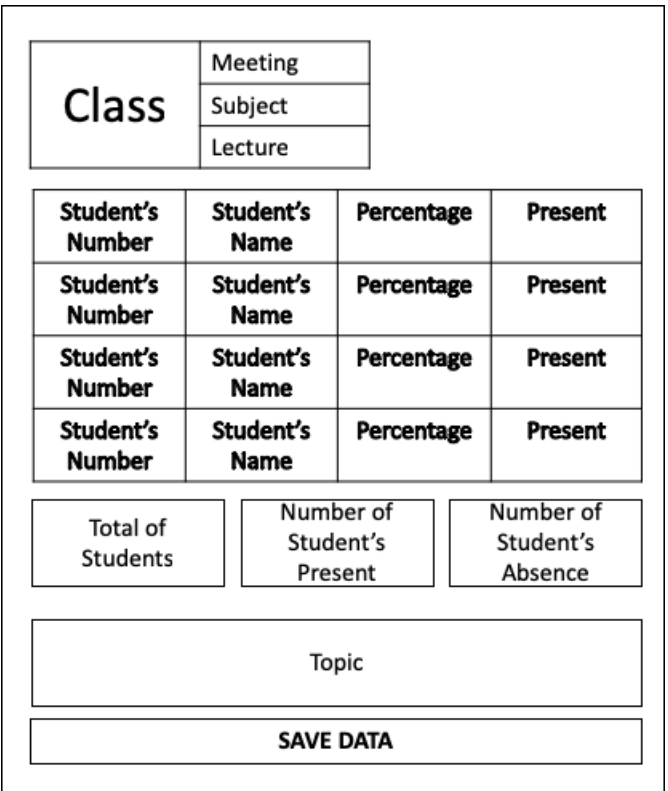

Fig. 3. Attendance menu in U-Mobile

Technically, the U-Mobile application was user-friendly, allowing the end-users to operate the application at their ease. During the pilot, none of the participants reported any technical issues. Instead, they mentioned that the application screen used soft colours in the background which was comfortable for their eyes. They also reported that the icon menus with the accompanying texts provided them with information about how to navigate in the application.

U-Mobile was observed to effectively capture the daily attendance of teachers and record each of the teaching sessions on a day-to-day basis. The data inputs to the system by the teachers were stored directly to two databases: the academic bureau and the faculty administration bureau. This allowed immediate communication to the related parties in the bureaus concerning the absences incurred [27].

However, we identified three critical issues concerning the application, namely processing time duration and system error, reporting and analytics issues, and input manipulation. Each of the issues is discussed below:

\subsection{Processing time and system error}

The processing time required for the application to store the data into the central database at the faculty administration was considered acceptable. As mentioned earlier, the attendance feature in the application required the teachers to not only mark their attendance but also monitor their students' entry into the classroom. The student monitoring activity had to be performed one by one by checking the students' names in the application to mark their attendance. Note that each marking attempt required 3-7 s for the system to store it into the central database. For a class of 40 students, the 
marking took approximately 3-7 min. The total time that the teachers spent to complete the tasks in the attendance menu ranged from 5 to 15 min depending on the speed of the Internet connection on the site.

All the participant teachers interviewed mentioned that tasks were frustrating because of a bad Internet connection on many sites across the faculty buildings. They also asserted that the marking menu icon frequently did not function well and displayed the message 'underdefined' (see Figure 4).

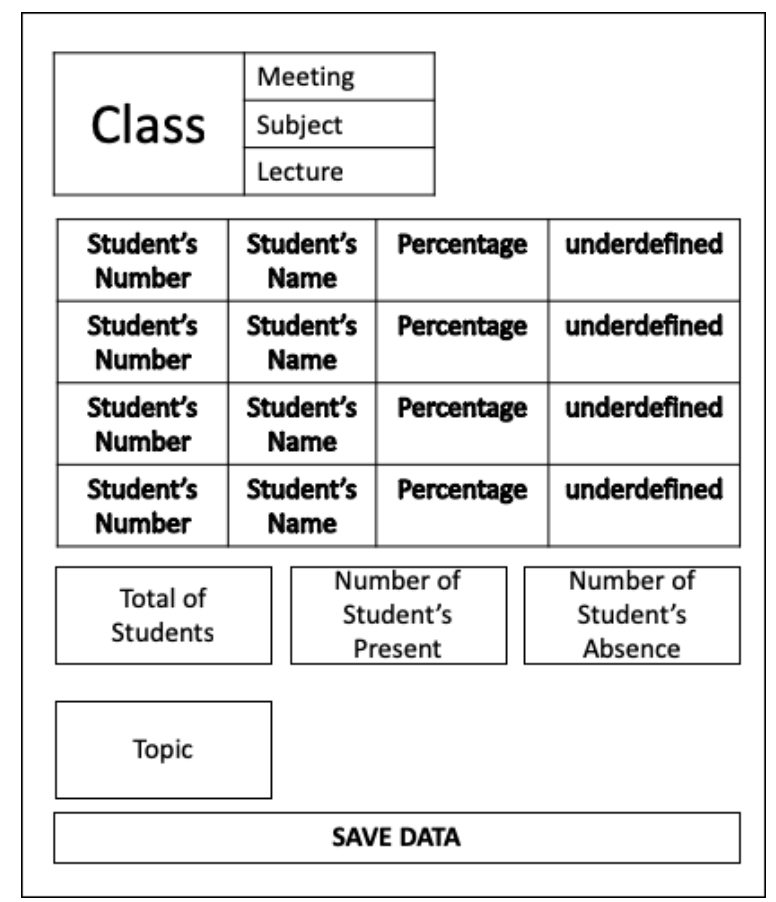

Fig. 4. System error in attendance feature

The effect of the long processing time and the system error was significant for the teachers. The teachers felt that monitoring students' attendance through the application reduced their teaching duration and thus affected their teaching plans. One of the teachers said:

'I tried several times to click on the menu, and it did not work at all. Obviously, this wasted my time. I had two teaching sessions of 100 min, and I spent more than 10 min only for this unsuccessful students' checking.' (Teacher B)

The teachers also reported the negative effect of the system error on their work performance and incentives. They mentioned that the error had caused them to not complete the required attendance set by the faculty administration and thus lowered the financial incentives they received. Teacher A confirmed:

'I lost about Rp. 300.000 (or USD 21) last month because of the system. I thought the system would automatically record my attendance when I marked the students' 
attendance in the application. But, in fact, it did not. I tried to clarify this issue to the administration. When I met them, I was told that the system recorded me as not attending the classroom teaching. They told me to also complete my teaching report manually. This was ineffective, really.' (Teacher A)

Many researchers have reported the role of financial incentives in improving teachers' attendance in teaching classrooms [17], [34], [35]. Balu and Ehrlich [35], for example, suggested that financial incentives could improve the teachers' attendance in the teaching classroom. The fact that the U-Mobile system error made it impossible to record the teachers' attendance appropriately might directly affect the teachers' financial incentives and thus would negatively impact the teachers' attendance in the future.

\subsection{Reporting and analytics issues}

As discussed earlier, U-Mobile benefited the faculty administration in that it helped them record the teachers' attendance on a daily basis [27]. Unfortunately, we observed that the system did not feature the report menu for teachers as the end-users. The absence of reporting menu has restricted teachers from generating their attendance reports and analytics. As in the case of Feature 3, the teachers were only informed about the percentage of students' attendance and the number of students attending the classroom sessions. Such an absence put the teachers at a disadvantage in that they were not given a tool to help them reflect on their participation in classroom teaching.

\subsection{Input manipulation}

Earlier, we mentioned that U-Mobile was integrated with the end-user phone's GPS system where it was allowed to use the end-user's position data and link it to the central database. This integration enabled the system to monitor the end-user's position and only allowed teachers to input data from a particular position. The findings from the observation and the interviews with the teachers revealed that many of the teachers manipulated their attendance by modifying the GPS data input. Teacher C said:

'I was surprised that I could mark my students' attendance from the traffic light which was more $500 \mathrm{~m}$ away from the main building I taught in." (Teacher C)

Although, many teachers believed that the input manipulation was motivated by their personal intention, but because of the U-Mobile system, they could not reliably record their position. Teacher A, for example, asserted:

'I believed something wrong had happened with the application. I was in Building $D$, but it was strange that the application restricted me from inputting the attendance data.' (Teacher $A$ )

Teacher B added:

'One of my students said to me that he could use the application from home. He showed me an application that allowed users to manipulate their position. I tried to download and install a fake GPS application into my phone. It worked!' (Teacher B) 


\section{Conclusions}

In the current study, we evaluated the development process and the application of U-Mobile as a technological tool to monitor teachers' attendance and their teaching activity at a private university in the capital city of Jakarta, Indonesia. The teachers perceived the use of U-Mobile to monitor their teaching attendance as positive. However, three main challenges were identified during the project implementation, namely processing time duration and system error, reporting and analytics issues, and input manipulation. The further development of U-Mobile should address these three challenges. In this current study, we only involved a small number of participants which accordingly could not represent the overall view of university teachers about the use of U-Mobile. Further research is thus needed to address the effectiveness and the teachers' perception of the AAMS application in higher education settings with a relatively large sample.

\section{$5 \quad$ References}

[1] L. Cucchiella, F; Gastaldi, M; Ranieri, 'Managing absenteeism in the workplace: The case of an Italian multiutility company', Procedia - Soc. Behav. Sci., vol. 150, pp. 1157-1166, 2014. https://doi.org/10.1016/j.sbspro.2014.09.131

[2] D. Griffith, Teacher absenteeism in charter and traditional public schools. Thomas B. Fordham Institute, 2017.

[3] F. Chaudhury, N; Hammer, J; Kremer, M; Muralidharan, K; Rogers, 'Missing in action: Teacher and health worker absence in developing countries', J. Econ. Perspect., vol. 20, no. 1, pp. 91-116, 2006. https://doi.org/10.1257/089533006776526058

[4] A. Sagie, 'Employee absenteeism, organizational commitment, and job satisfaction: Another look', J. Vocat. Behav., vol. 52, pp. 156-171, 1998. https://doi.org/10.1006/jvbe. 1997.1581

[5] H. Salih, 'Staff absenteeism: The case of wa municipal education office of the Ghana education service’, Open J. Soc. Sci., vol. 6, pp. 1-14, 2018. https://doi.org/10.4236/jss.2018.6 $\underline{8001}$

[6] J. Ost, B; Schiman, 'Workload and teacher absence', Econ. Educ. Rev., vol. 57, pp. 20-30, 2017.

[7] M. Ronning, 'The effect of working conditions on teachers' sickness absence', Oslo, Discussion Papers, No. 684, Statistics Norway, Research Department, 2012.

[8] S. Medeiros, A; Assuncao, A; Barreto, 'Absenteeism due to voice disorders in female teachers: A public health problem', Int arch occup Env. Heal., vol. 85, pp. 853-864, 2012. https://doi.org/10.1007/s00420-011-0729-1

[9] J. Denteh, W; Yeboah, E; Sam, C; Monkah, 'The impact of student and teacher absenteeism on student performance at the junior high school: The case of the Kumasi Metro school district', Cont. J. Educ. Res., vol. 4, no. 1, pp. 7-17, 2011.

[10] J. Miller, R; Murnane, R; Willett, 'Do teacher absences impact student achievement? Longitudinal evidence from one urban school district', Educ. Eval. Policy Anal., vol. 30, no. 2, pp. 181-200, 2008. https://doi.org/10.3386/w13356

[11] A. Abayasekara and N. Arunatilake, 'School-level resource allocation and education outcomes in Sri Lanka', Int. J. Educ. Dev., vol. 61, pp. 127-141, 2018. https://doi.org/10.1016 /j.ijedudev.2017.12.010 
[12] M. Sabarwal, S; Jawdeh, 'What teachers believe: Mental models about accountability, absenteeism, and student learning', Policy Research Working Paper 8454, World bank group: Education global practice, 2018. https://doi.org/10.1596/1813-9450-8454

[13] E. Davies, 'Absence: Electoral cycles and teacher absenteeism in India', Polit. Econ. Educ., 2018.

[14] S. Usman, Akhmadi, D. Suryadarma, and D. Usman, S; Suryadarma, 'Patterns of teacher absence in public primary schools in Indonesia', Asia Pacific J. Educ., vol. 27, no. 2, pp. 207-219, 2007. https://doi.org/10.1080/02188790701378826

[15] N. Iqbal, N; Muhammad, S; Haider, 'To explore the causes of absenteeism at government and private primary schools: A case study from Pakistan', Int. Lett. Soc. Humanist. Sci., vol. 54, pp. 21-25, 2015. https://doi.org/10.18052/www.scipress.com/ilshs.54.21

[16] J. Mooij, 'Primary education, teachers' professionalism and social class about motivation and demotivation of government school teachers in India', Int. J. Educ. Dev., vol. 28, no. 5, pp. 508-523, 2008. https://doi.org/10.1016/j.ijedudev.2007.10.006

[17] P. McKenzie, D. Nugroho, C. Ozolins, J. McMillan, and S. Sumarto, 'Teachers absenteeism in Indonesia: Policy brief', Teach. Learn. Leadersh., vol. 11, 2014.

[18] M. Dullo; Esther; Dupas, P; Kremer, 'Peer effects, teacher incentives, and the impact of tracking: Evidence from a randomized evaluation in Kenya', Am. Econ. Rev., pp. 17391774, 2011. https://doi.org/10.1257/aer.101.5.1739

[19] I. Ujan, E; Ismaili, I. A. Ujan, and I. A. Ismaili, 'Biometric attendance system', in Complex Medical Engineering (CME), 2011 IEEE/ICME International Conference on, 2011, pp. 499-501. https://doi.org/10.1109/iccme.2011.5876792

[20] A. Agrawal, A; Bansal, 'Online attendance management system using RFID with object counter', Int. J. Inf. Comput. Technol., vol. 3, no. 3, pp. 131-138, 2013.

[21] L. Ezema, L; Uzuegbu, C; Eneh, J; Amanze, 'Fingerprint based attendance management system', Int. J. Sci. Eng. Res., vol. 6, no. 7, 2015.

[22] R. Shakil, M; Nandi, 'Attendance management system for industrial worker using finger print scanner', Glob. J. Comput. Sci. Technol., vol. 13, no. 6, 2013.

[23] C. Baffoe, 'A proposed GSM biometric attendance management system for Ghana education', Int. J. Adv. Netw. Appl., vol. 9, no. 3, pp. 3421-3427, 2017.

[24] N. I. Zainal, K. A. Sidek, T. S. Gunawan, H. Manser, M. Kartiwi, and M. Zainal, N; Sidek, K; Gunawan, T; Mansor, H; Kartiwi, 'Design and development of portable classroom attendance system based on Arduino and fingerprint Biometric', in Information and Communication Technology for The Muslim World (ICT4M), 2014 The 5th International Conference on, 2014, pp. 1-4. https://doi.org/10.1109/ict4m.2014.7020601

[25] S. Joshi, R; Shete, V; Somani, 'Android based smart learning and attendance management system’, Int. J. Adv. Res. Comput. Commun. Eng., vol. 4, no. 6, pp. 250-260, 2015.

[26] P. Bhattacharjee, S; Kundu, D; Raychaudhuri, S; Chakraborty, 'Attendance management system an Android application’, Int. J. Comput. Sci. Eng., vol. 4, no. 6, 2016.

[27] L. P. I. Almiranez, G; Mercado, J; Aumentado, 'Ensuring quality performance of faculty attendance management system', 2017.

[28] B. J. Fishman, W. R. Penuel, A.-R. Allen, B. H. Cheng, and N. Sabelli, 'Design-based implementation research: An emerging model for transforming the relationship of research and practice', Natl. Soc. Study Educ., vol. 112, no. 2, pp. 136-156, 2013.

[29] T. Anderson and J. Shattuck, 'Design-based research: A decade of progress in education research?', Educ. Res., vol. 41, no. 1, pp. 16-25, 2012.

[30] Y. Y. Sari, S. Zulaiha, and H. Mulyono, 'The development of a digital application to promote parents' involvement in a character education at primary schools', Pap. Rev., 2019. 
[31] S. Kratky and C. Reichenberger, 'Client/Server Development based on the Apple Event Object Model', Atlanta, 2013.

[32] A. A. Kumbhar, K. S. Wanjara, D. H. Trivedi, A. U. Khairatkar, and D. Sharma, 'Automated attendance monitoring system using android platform', Int. J. Curr. Eng. Technol., vol. 4, no. 2, pp. 1096-1099, 2014.

[33] H. S. Oluwatosin, 'Client-server model', IOSRJ Comput. Eng, vol. 16, no. 1, pp. 2278$8727,2014$.

[34] E. Duflo, R. Hanna, and S. P. Ryan, 'Incentives work: Getting teachers to come to school', Am. Econ. Rev., vol. 102, no. 4, pp. 1241-1278, 2012. https://doi.org/10.1257/aer.102.4.1 $\underline{241}$

[35] R. Balu and S. B. Ehrlich, 'Making Sense out of Incentives: A Framework for Considering the Design, Use, and Implementation of Incentives to Improve Attendance', J. Educ. Students Placed Risk, vol. 23, no. 1-2, pp. 93-106, 2018. https://doi.org/10.1080/10824669.20 $\underline{18.1438898}$

\section{Authors}

Suryaman is an associate professor Universitas Islam Raden Rahmat, Indonesia. He obtained his Ph.D at State University of Malang, Indonesia. His research interests include education management and leadership, classroom management, integration of ICT in education settings. E-mail: maman_suryaman58@yahoo.co.id

Herri Mulyono is a senior lecture at University of Muhammadiyah Prof. DR. HAMKA, Indonesia. He obtained his Ph.D at University of York. UK. His research interests include teaching English as a foreign language, computer assisted language learning (CALL), and teacher professional development.

Article submitted 2019-02-04. Resubmitted 2019-05-17. Final acceptance 2019-05-17. Final version published as submitted by the authors. 